\title{
Rheological Study on ATBS-AM Copolymer-Surfactant System in High-Temperature and High-Salinity Environment
}

\author{
Muhammad Shahzad Kamal, ${ }^{1}$ Ibnelwaleed Ali Hussien, \\ Abdullah Saad Sultan, ${ }^{2}$ and Ming $\mathrm{Han}^{3}$ \\ ${ }^{1}$ Department of Chemical Engineering, King Fahd University of Petroleum and Minerals, Dhahran 31261, Saudi Arabia \\ ${ }^{2}$ Department of Petroleum Engineering and Center of Petroleum and Minerals, King Fahd University of Petroleum and Minerals, \\ Dhahran 31261, Saudi Arabia \\ ${ }^{3}$ EXPEC Advanced Research Center, Saudi Aramco, Dhahran 31311, Saudi Arabia
}

Correspondence should be addressed to Abdullah Saad Sultan; sultanas@kfupm.edu.sa

Received 7 May 2013; Accepted 21 June 2013

Academic Editor: Yujun Feng

Copyright (C) 2013 Muhammad Shahzad Kamal et al. This is an open access article distributed under the Creative Commons Attribution License, which permits unrestricted use, distribution, and reproduction in any medium, provided the original work is properly cited.

\begin{abstract}
Experimental studies were conducted to evaluate the rheological properties of surfactant-polymer (SP) system. This SP system consists of a copolymer of acrylamide (AM) and acrylamido tertiary butyl sulfonate (ATBS) and sodium dodecyl sulphate (SDS) surfactant. Effects of surfactant concentration, temperature, polymer concentration, and salinity on rheological properties of SP system were investigated by means of oscillation and shear measurements. Comparison with classical partially hydrolyzed polyacrylamide (HPAM) was made. For the same temperature range, the viscosity drop for HPAM was about four times higher than the viscosity drop for ATBS-AM copolymer. In deionized water, viscosity of both polymers and SP systems was very high as compared to viscosity in saline water. Viscosity reduction of ATBS-AM copolymer was higher for salts having divalent cations. The SP system showed precipitation in presence of divalent cations. It worked well with monovalent cations even at relatively high salinities. The addition of $0.1 \%$ surfactant to the polymer resulted in a $60 \%$ decrease in the viscosity. Some interfacial rheological experiments were also carried out to investigate the behaviors on the interface between SP solutions and oil. Addition of $0.1 \%$ surfactant showed a $65 \%$ decrease in $G^{\prime}$ at SP solution-oil interface. SP system consisting of ATBS-AM and SDS showed better performance at high temperature compared to HPAM-SDS system. Due to precipitation, the SP system should be restricted to environment having low divalent cations.
\end{abstract}

\section{Introduction}

In chemical enhanced oil recovery (cEOR), surfactants are used to reduce the interfacial tension between crude oil and water. Polymers are used to improve the mobility ratio by viscosifying displacing fluid. Enhanced viscosity of displacing fluids can increase macroscopic displacement efficiency by overcoming viscous fingering. Recently, some researchers have proved that these polymers not only improve macroscopic displacement efficiency but also microscopic efficiency due to elasticity [1-7].
HPAM which is widely used for cEOR applications [8] fails at high-temperature and high-salinity (HTHS) environment. Extensive hydrolysis of amide group at high temperatures may also cause precipitation of hydrolyzed product in the presence of divalent cations. Field applications of available polymers are limited to low-temperature and low-salinity reservoirs. HTHS reservoirs present a major challenge for implementation of cEOR techniques. Incorporation of some thermally stable and salt tolerant comonomers can enhance the performance of polyacrylamide in HTHS conditions. Recently, synthesized thermoviscosifying polymers [9-12] 
showed some positive results in HTHS environment after some preliminary rheological tests.

Three major types of surfactant-polymer interactions may exist depending upon the nature and structure of polymer and surfactant head group. Firstly, attractive forces between surfactant and polymer may be stronger than mutual forces of surfactant molecule. Secondly, attractive forces among surfactant molecules may be greater than attractive forces between surfactant and polymer. Thirdly, repulsive forces between surfactant and polymer are very high as compared to attractive forces among surfactant molecules [13]. The system becomes more complex in the presence of oil, cosurfactant, alkali, and salts. Many approaches have been adopted to understand the interactions between surfactant-polymer systems. These include surface tension and interfacial tension measurement, rheology [14-17], fluorescence spectroscopy [18-20], potentiometry [21], light scattering [22, 23], and conductivity measurement [2428].

There are some reports available in the literature on the rheology of classical HPAM/SDS [15] PAM/SDS [29] and hydrophobically modified PAM (HM-PAM)/SDS [14] system. Addition of the surfactant has no effect on the rheology of the polymer due to nonionic nature of PAM. Significant effect of surfactant addition has been reported for HPAM and HM-HPAM due to strong interactions between the surfactant and polymer. By addition of $30 \mathrm{mmol} / \mathrm{L}$ $(0.86 \%)$ SDS, about $85 \%$ drop in the viscosity of HPAM is reported byBu et al. [17]. SP solution consisting of SDS and vinylpyridine-AM copolymer in $0.1 \mathrm{~N} \mathrm{NaCl}$ solution has about $90 \%$ less viscosity than that of the viscosity of the SP solution in deionized water [16]. Temperature also plays an important role in surfactant-polymer interactions. For HM-HPAM/SDS system, Nystrom [29] found that the viscosity at $40^{\circ} \mathrm{C}$ is $80 \%$ less than that of viscosity at $10^{\circ} \mathrm{C}$.

Rheology study can be used to screen many SP systems for cEOR applications. In addition, interfacial rheology can provide the insight on the interface between SP solution and oil. The objective of this work is to study the influence of salts, temperature, and surfactant concentration on rheological properties of SP system consisting of SDS and ATBS-AM copolymer. Some of the results were compared with HPAM.

\section{Experimental}

2.1. Materials. Copolymer of AM and ATBS (Flopaam An125SH) with a molecular weight of 8 million Dalton and $25 \%$ sulfonation degree was obtained from SNF FLOERGER in a powder form. Classical HPAM (Flopaam 3630S) with a molecular weight of 20 million Dalton and 30\% hydrolysis degree was obtained from SNF FLOERGER. Sea water was prepared using laboratory grade sodium bicarbonate, sodium sulphate, sodium chloride, calcium chloride, and magnesium chloride with a total salinity of $57,638 \mathrm{mg} / \mathrm{L}$ (ppm). SDS with $99 \%$ purity was obtained from Sigma Aldrich. The oil used in interfacial rheology experiments has a density of $0.8767 \mathrm{~g} / \mathrm{cm}^{3}$.
2.2. Preparation of Polymer Solutions. A polymer solution was prepared by using magnetically driven stirrer. The polymer was added slowly on the shoulder of the vortex formed by deionized water, surfactant solution, or salt solution to avoid formation of slubs. As soon as the entire polymer was added the rotor speed was reduced from 300 to $80 \mathrm{rpm}$ to avoid mechanical degradation. Stirring was turned off after 3 hours and the solution was kept at room temperature for the next 48 hours for complete hydration.

2.3. Rheological Measurements. Rheological measurements were carried out using discovery hybrid rheometer (DHR3) from TA Instrument. Concentric cylinder geometry was used to measure both steady state and oscillation measurements. The range of shear rate for steady shear viscosity measurements was from 0.01 to $1000 \mathrm{~s}^{-1}$. Frequency from 0.1 to $100 \mathrm{rad} / \mathrm{s}$ was applied for oscillatory measurements. All reported data points are within torque limits $( \pm 5 \mathrm{mN} \cdot \mathrm{m}-2000 \mathrm{mN} \cdot \mathrm{m})$. Frequency sweep experiments were conducted in the linear viscoelastic region. Oscillation time experiment was performed to check the thermal stability of HPAM and ATBS-AM copolymer. Interfacial rheology experiments were performed using AR-G2 platinum double wall ring interfacial geometry. Frequency was kept at $1 \mathrm{rad} / \mathrm{s}$ in oscillation time and temperature ramp experiments unless it is stated otherwise.

\section{Results and Discussion}

3.1. Effect of Surfactant Concentration. Copolymer concentration was fixed to $0.25 \%$ for experiments with varying surfactant concentration. Unless otherwise specified, the term copolymer in this discussion refers to ATBS-AM copolymer. Figure 1 shows the viscosity versus shear rate plots of $0.25 \%$ copolymer in deionized water for different concentrations of surfactant. It is evident from Figure 1 that by increasing the surfactant concentration steady viscosity is decreasing. The viscosity of the SP system is low compared to the viscosity of copolymer. By adding $0.3 \%$ surfactant, the viscosity is $80 \%$ less than that of the viscosity of the copolymer. Similar degree of viscosity drop by adding SDS has been reported for HPAM $[15,17]$. This decrease in viscosity by the addition of surfactant is due to charge shielding mechanism as reported by Mandal and Ojha [15] for HPAM. At very high shear rate, viscosity is almost the same for all surfactant concentrations due to the dominance of the effect of shear in comparison to charge interactions. Variation of complex viscosity at a frequency of $0.1 \mathrm{rad} / \mathrm{s}$ is also shown in Figure 2. Storage modulus, $G^{\prime}$, versus surfactant concentration is shown in Figure 3. $G^{\prime}$ decreases with the increase in surfactant concentration. As $\mathrm{G}^{\prime}$ is a measure of elastic nature, it is obvious that addition of surfactant is causing loss in network structure of ATBSAM copolymer. Interfacial rheological properties were also evaluated at oil/SP solution interface to examine the influence of surfactant concentration. Figure 4 shows the interfacial storage modulus $\left(G_{I}^{\prime}\right)$ versus frequency curves at different surfactant concentrations. At all frequencies, $G_{I}^{\prime}$ decreases by increasing surfactant concentration. We can conclude that 


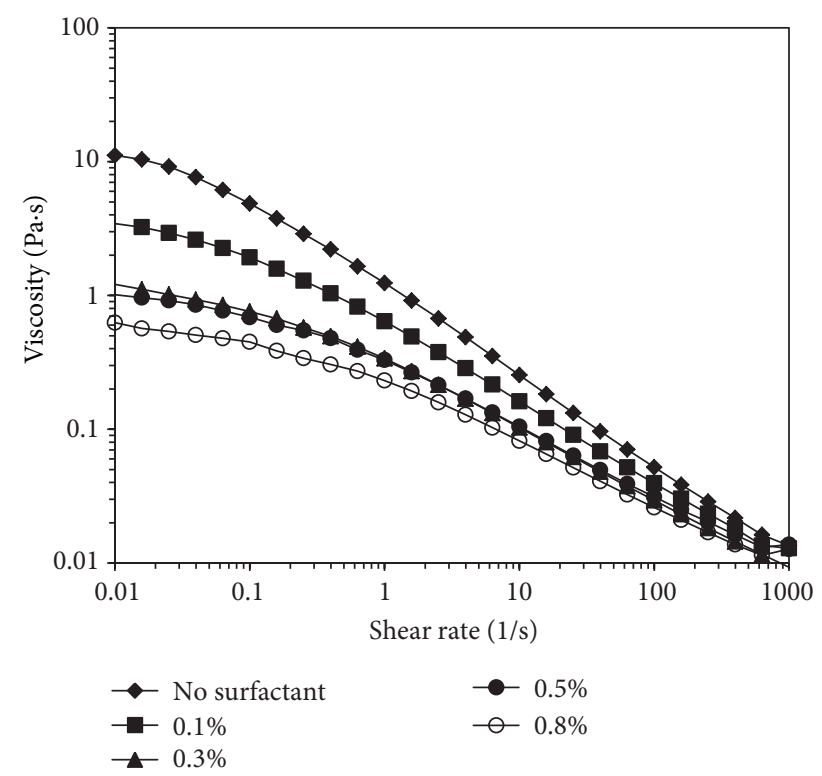

FIGURE 1: Effect of surfactant concentration on steady shear viscosity of copolymer at different shear rates in deionized water at $50^{\circ} \mathrm{C}$.

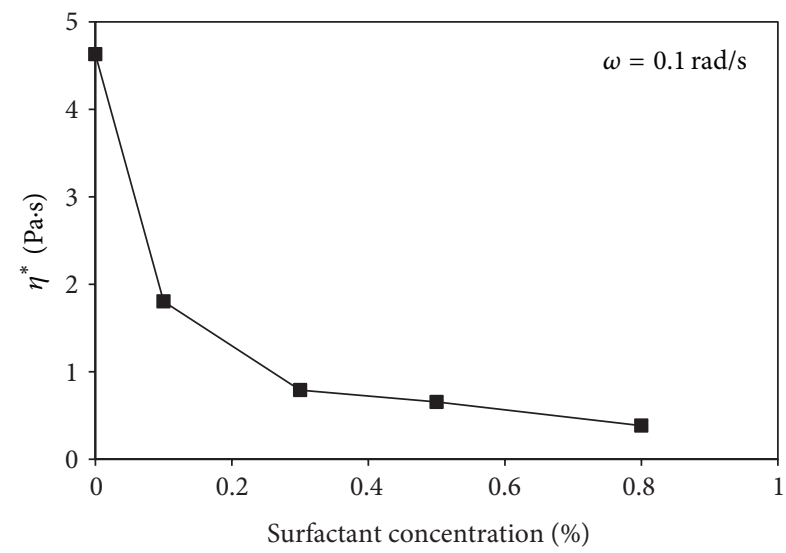

FIGURE 2: Effect of surfactant concentration on complex viscosity of copolymer in deionized water at $50^{\circ} \mathrm{C}$.

addition of surfactant is weakening the interface between oil and SP solution. Time sweep measurements were also carried out to determine $G_{I}^{\prime}$. These measurements were performed for 5 minutes and within experimental time no change in storage modulus was observed. Results of time sweep experiment are shown in Figure 5. A major drop in $G_{I}^{\prime}$ due to addition of $0.1 \%$ surfactant is observed, while, further addition of the surfactant has little effect.

3.2. Effect of Temperature. Viscosity versus shear rate plots for HPAM and ATBS-AM copolymer in the absence of surfactant is obtained at two different temperatures (Figure 6). It is evident that increasing temperature from $50^{\circ} \mathrm{C}$ to $90^{\circ} \mathrm{C}$ causes a major drop in steady shear viscosity of HPAM as compared to the copolymer. At low shear rate, the viscosity of HPAM at $90^{\circ} \mathrm{C}$ is about $60 \%$ less than its viscosity at $50^{\circ} \mathrm{C}$. However,

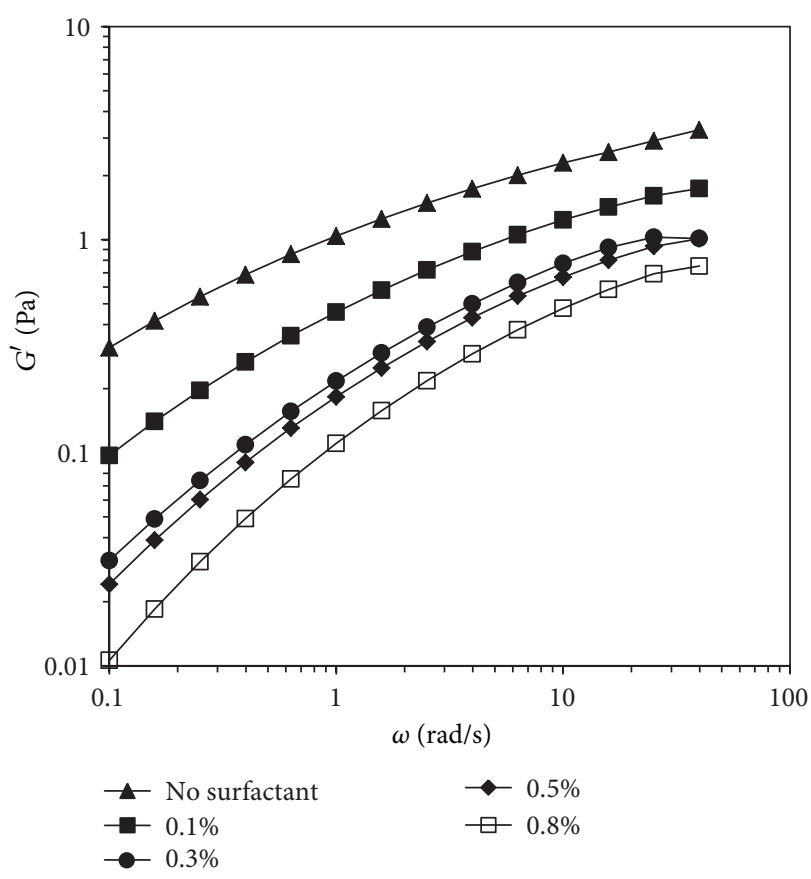

FIGURE 3: Effect of surfactant concentration on storage modulus of copolymer at different frequencies in deionized water at $50^{\circ} \mathrm{C}$.

for ATBS-AM copolymer, small change in viscosity (15\%) was observed in the same temperature range. This suggests that the viscosity of ATBS-AM copolymer is less sensitive to temperature in comparison with HPAM. Time sweep experiments were run for two hours for both polymers at $50^{\circ} \mathrm{C}$ and $90^{\circ} \mathrm{C}$ and results are shown in Figure 7. Both polymers were stable at $50^{\circ} \mathrm{C}$ within the experimental time. Within the experimental time, $G^{\prime}$ and viscosity (not shown) did not change for both polymers. At $90^{\circ} \mathrm{C}$, completely different results were found. Unlike ATBS-AM copolymer a continuous decrease in storage modulus of HPAM was observed as experiment proceeds. From the above results it can be concluded that at $50^{\circ} \mathrm{C}$ both polymers show good stability and can be used at this temperature. However, at $90^{\circ} \mathrm{C}$ HPAM shows a continuous decrease in rheological properties while AM-ATBS copolymer is stable.

Figures 8 and 9 present results of temperature ramp experiments at $2^{\circ} \mathrm{C} / \mathrm{min}$ for different surfactant concentrations. Viscosity versus temperature plots are shown in Figure 8. At all temperatures, the viscosity of the polymer and SP solutions is decreasing with increasing surfactant concentrations. However, the decrease in viscosity depends on the concentration of surfactant. With no surfactant added in the solution, $20 \%$ decrease in viscosity was observed in the temperature range $30^{\circ} \mathrm{C}$ to $85^{\circ} \mathrm{C}$. With the addition of $0.1 \%$ surfactant, the viscosity decreases by $33 \%$ for the same temperature range. For $0.3 \%$ and higher surfactant concentrations about $58 \%$ drop in viscosity was observed. For HMHPAM/SDS system $80 \%$ viscosity decrease was observed when temperature was increased from 10 to $40^{\circ} \mathrm{C}$ [29]. This shows that ATBS-AM/SDS system perform much better in high temperature compared to HM-HPAM/SDS system. 


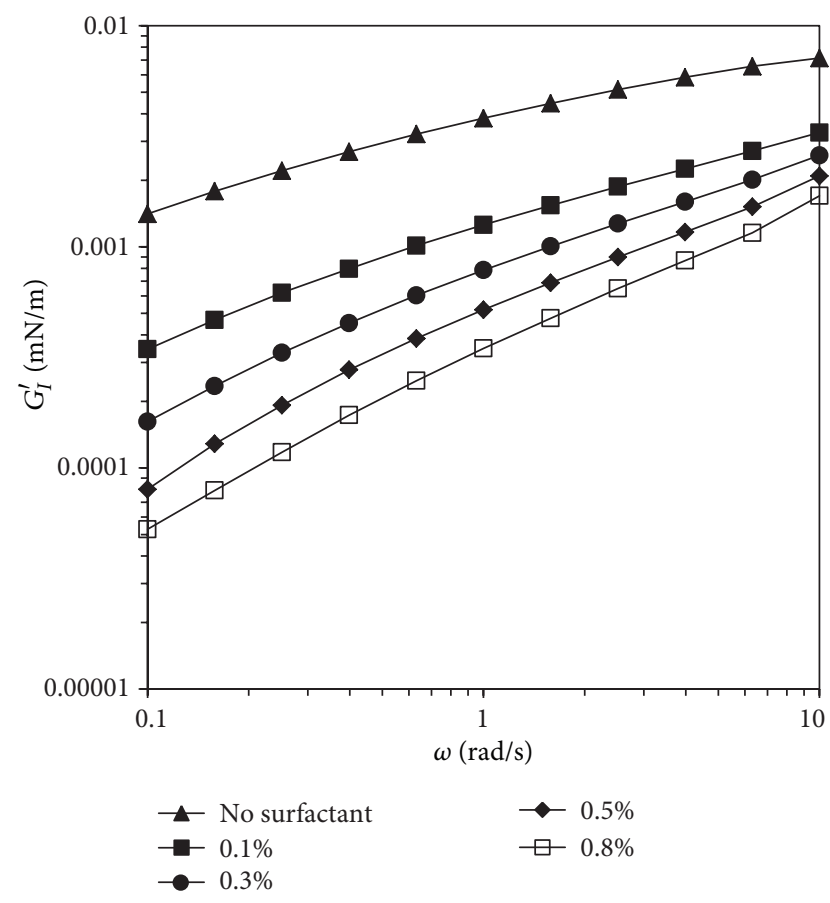

FIGURE 4: Effect of surfactant concentration on interfacial storage modulus of copolymer at different frequencies in deionized water at $25^{\circ} \mathrm{C}$.

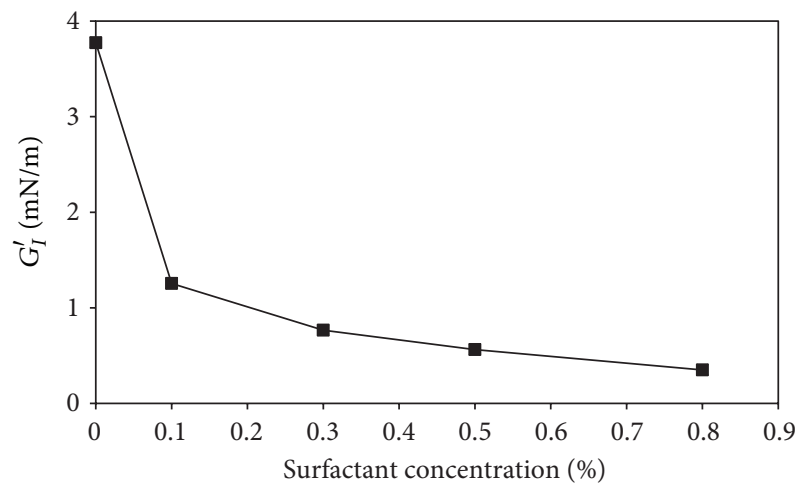

FIGURE 5: Effect of surfactant concentration on interfacial storage modulus of copolymer in deionized water at $25^{\circ} \mathrm{C}$.

Arrhenius model was used to obtain activation energy of viscous flow and pre-exponential factor for solution of different surfactant concentrations. Activation energy of viscous flow increased while pre-exponential factor decreased with the addition of surfactant (Table 1). The percentage decrease in the pre-exponential factor is high as compared to the percentage increase in the activation energy. The above data indicate that in the presence of a surfactant, temperature has more effect on the viscosity of SP solutions as compared to copolymer solution having no surfactant. Similarly, for polymer solution without surfactant, a $26 \%$ drop in $G^{\prime}$ was noted. For $0.3 \%$ and higher surfactant concentrations about $70 \%$ decrease in storage modulus was observed in the same temperature range. Effect of temperature on $G_{I}^{\prime}$ is shown in
TABLE 1: Activation energy and pre-exponential factors obtained from Arrhenius model for different surfactant concentrations.

\begin{tabular}{lcc}
\hline Concentration $(\%)$ & $E_{a}{ }^{\mathrm{a}}(\mathrm{kJ} / \mathrm{mole})$ & $A^{\mathrm{b}}(\mathrm{mPa} \cdot \mathrm{s})$ \\
\hline 0 & 5.020 & 210.74 \\
0.1 & 7.010 & 45.177 \\
0.3 & 14.54 & 1.2797 \\
0.5 & 15.38 & 0.8152 \\
0.8 & 15.877 & 0.5497 \\
\hline
\end{tabular}

${ }^{\mathrm{a}} E_{a}$ is activation energy of viscous flow.

${ }^{\mathrm{b}} A$ is pre-exponential factor.

TABLE 2: Activation energy and pre-exponential factors obtained from Arrhenius-type relation for different polymer concentrations.

\begin{tabular}{lcc}
\hline Concentration $(\%)$ & $E_{a}{ }^{\mathrm{a}}(\mathrm{kJ} / \mathrm{mole})$ & $A^{\mathrm{b}}(\mathrm{mPa} \cdot \mathrm{s})$ \\
\hline 0.15 & 18.32 & 0.4266 \\
0.20 & 16.94 & 1.1205 \\
0.25 & 14.54 & 1.2797 \\
0.30 & 14.90 & 5.0728 \\
0.40 & 13.86 & 12.891 \\
\hline
\end{tabular}

${ }^{\mathrm{a}} E_{a}$ is activation energy of viscous flow.

${ }^{\mathrm{b}} A$ is pre-exponential factor.

Figure 10. With the increase in temperature $G_{I}^{\prime}$ also decreases. This shows that temperature is also weakening the interface, but its effect is not as much when we compare it to the effect of surfactant concentrations. The surfactant concentration is a major source of reduction in interfacial rheological properties between SP solution and oil interface.

3.3. Effect of Polymer Concentration. Surfactant concentration was fixed to $0.3 \%$ for all experiments and polymer concentration was varied from 0.1 to $0.4 \%$. Figures 11 and 12 summarize the effect of polymer concentration on SP system. No unusual results were observed by changing the polymer concentration. It is clear from Figures 11 and 12 that increasing the concentration of polymer will cause increase in steady shear viscosity. This increase is more prominent at low shear rate. Results of temperature ramp experiments at a rate of $2^{\circ} \mathrm{C} / \mathrm{min}$ for different copolymer concentrations are shown in Figures 13 and 14. Both storage modulus and viscosity decrease with increasing in temperature at all polymer concentration. However, the decrease in the viscosity and storage modulus depends on the polymer concentration. Maximum drop in viscosity (58\%) and storage modulus (70\%) was found for SP solution having minimum polymer concentration (0.15\%) and minimum drop in viscosity (49\%) and storage modulus (57\%) was found with SP solution of highest polymer concentration $(0.4 \%)$. Activation energy of viscous flow and pre-exponent factors for SP solutions of different polymer concentrations were calculated and tabulated in Table 2. Pre-exponent factor and activation energy of viscous flow of the SP solutions do not change significantly by changing the polymer concentration. However, slight change in surfactant concentration significantly changes the preexponent factor and activation energy of the SP solutions. 


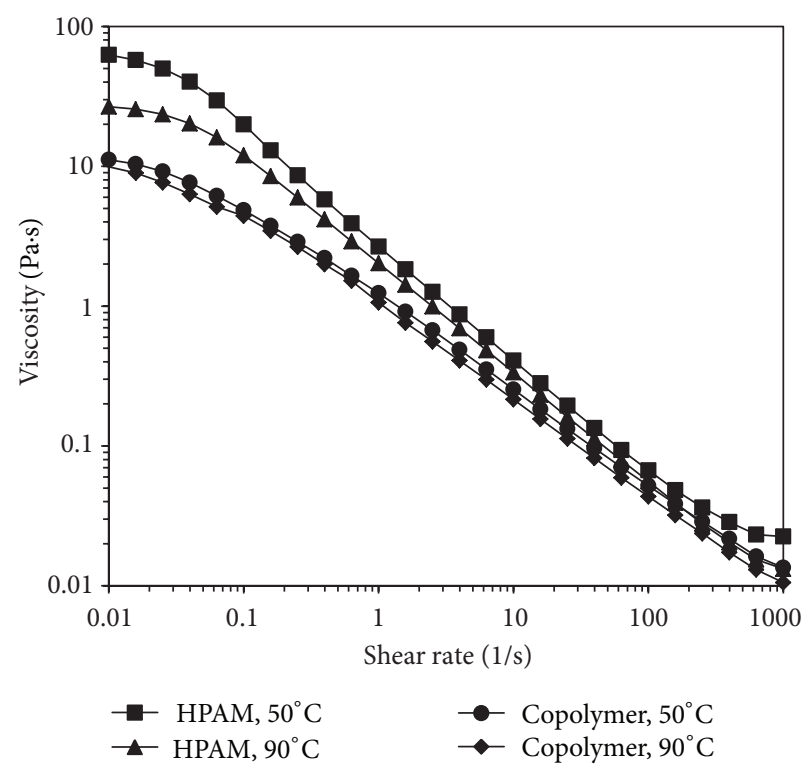

FIGURE 6: Steady shear viscosity profile of HPAM and ATBS-AM copolymer solutions in salt-free water without surfactant at $0.25 \%$ polymer concentration.

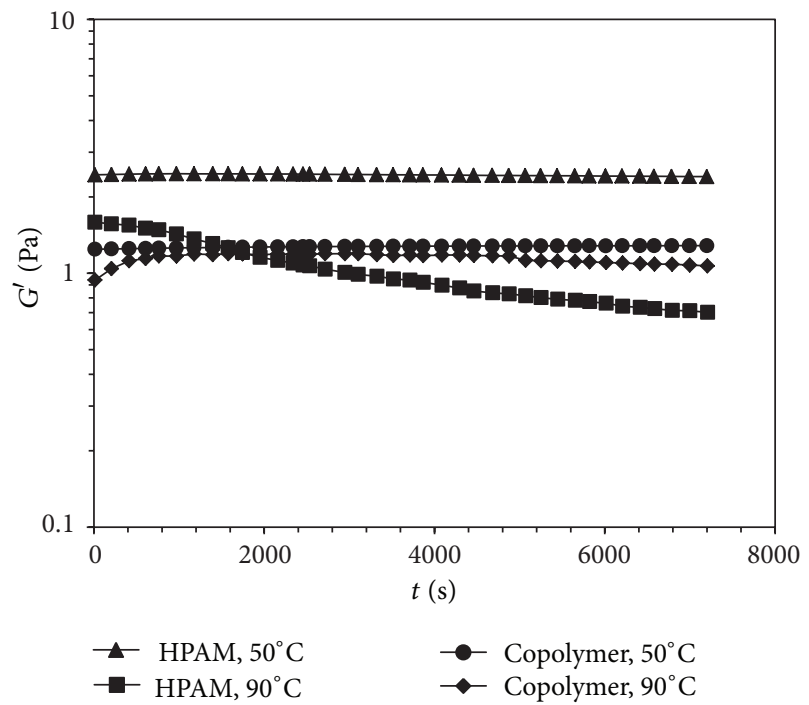

FIGURE 7: Comparison of $G^{\prime}$ of HPAM and ATBS-AM copolymer solutions in deionized water by time sweep measurements at $0.25 \%$ polymer concentration.

Decrease in the viscosity with temperature depends mainly on surfactant concentration and polymer concentration has little effect.

3.4. Effect of Salts. High temperatures and high salinities are real challenges for polymer flooding for the Middle East carbonate reservoirs. In the presence of salts and higher temperatures, viscosity of HPAM decreases. Synthetic sea water with a total salinity of $57638 \mathrm{mg} / \mathrm{L}$ containing $2732 \mathrm{mg} / \mathrm{L}$ divalent cations was prepared in the lab. It is important to see the effect of each individual ion on the SP system used for

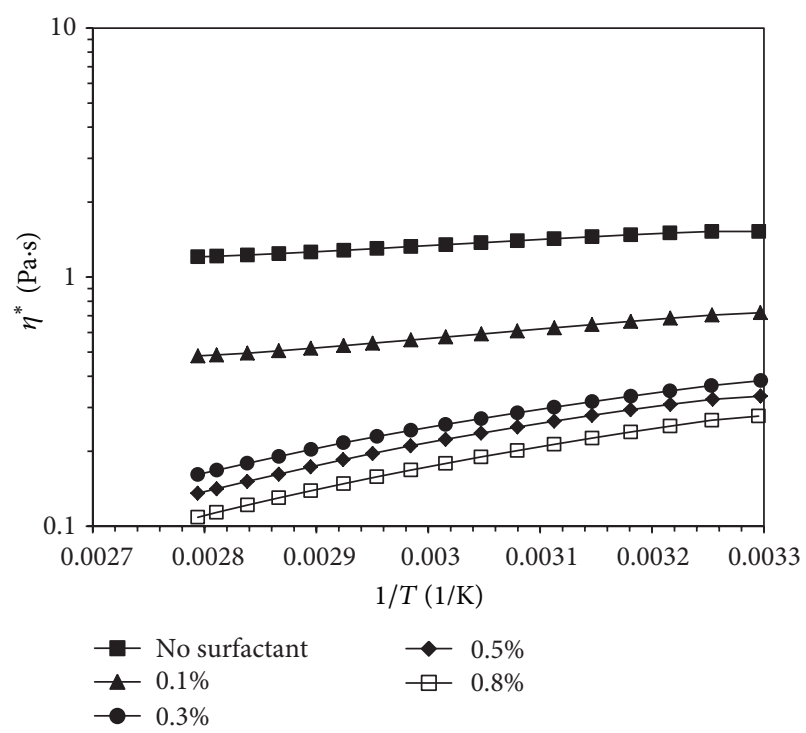

FIGURE 8: Effect of temperature on viscosity of $0.25 \%$ copolymer at different surfactant concentration.

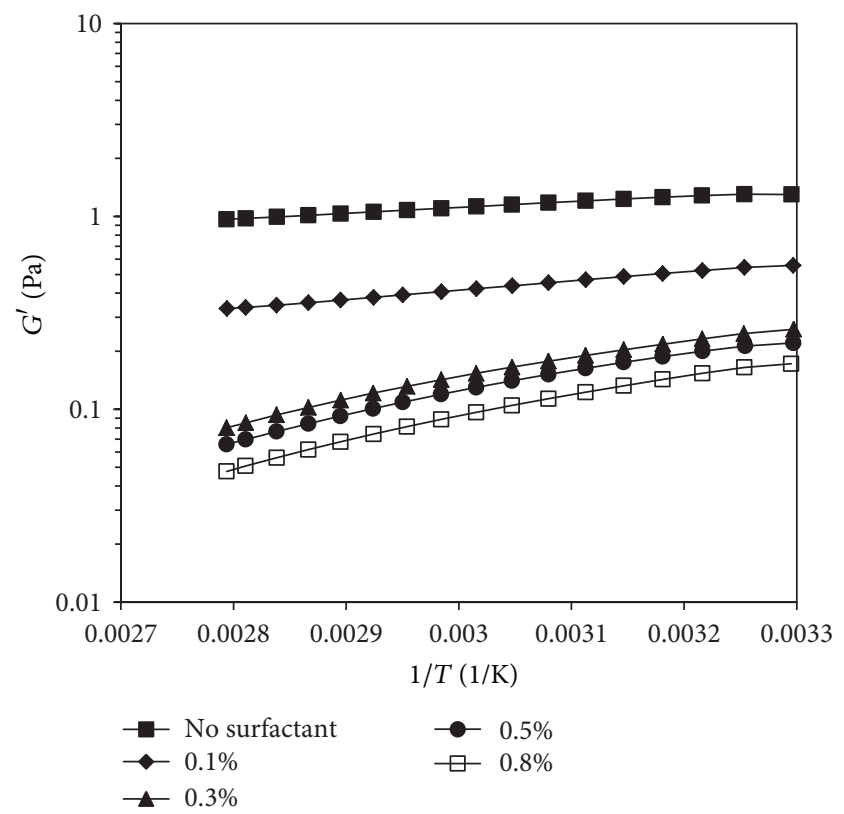

FIGURE 9: Effect of temperature on $G^{\prime}$ of $0.25 \%$ copolymer at different surfactant concentration.

chemical flooding. Besides sea water salt solutions of $\mathrm{NaCl}$, $\mathrm{Na}_{2} \mathrm{SO}_{4}, \mathrm{MgCl}_{2}$, and $\mathrm{CaCl}_{2}$ were prepared with different molarities. SP solutions of $0.25 \%$ polymer and $0.3 \%$ surfactant concentration were used to evaluate the performance in different salts. Figure 15 shows the comparison of viscosity of both polymers in deionized water at $50^{\circ} \mathrm{C}$ without a surfactant. A major reduction in viscosity was observed for both polymers by adding synthetic sea water. Figures 16 and 17 show the effect of sodium chloride concentration on rheological properties of SP system. Steady shear viscosity reduces as the concentration of sodium chloride is increased. 


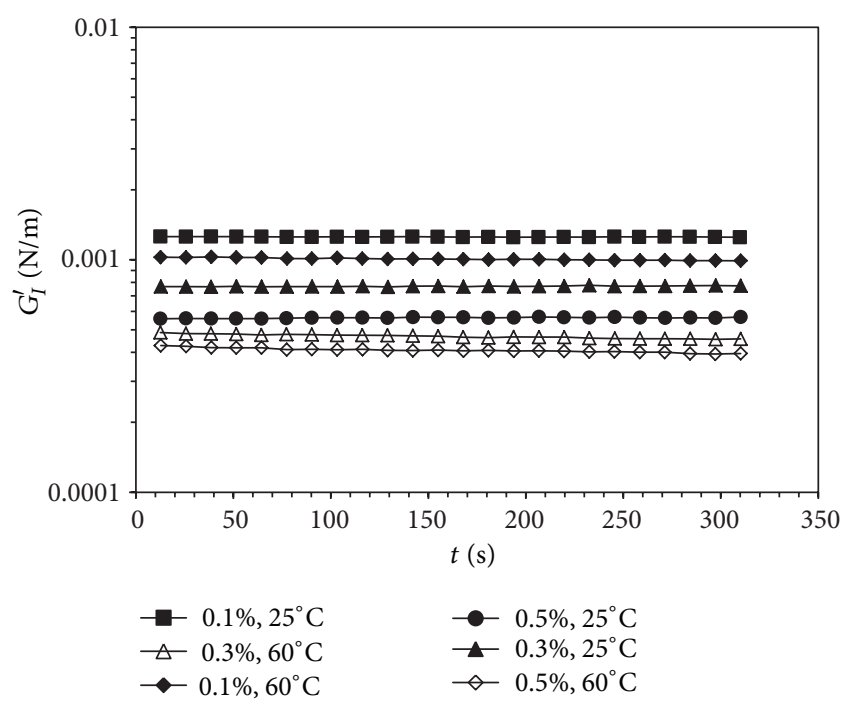

FIGURE 10: Effect of temperature on $G_{I}^{\prime}$ of $0.25 \%$ copolymer at different surfactant concentration.

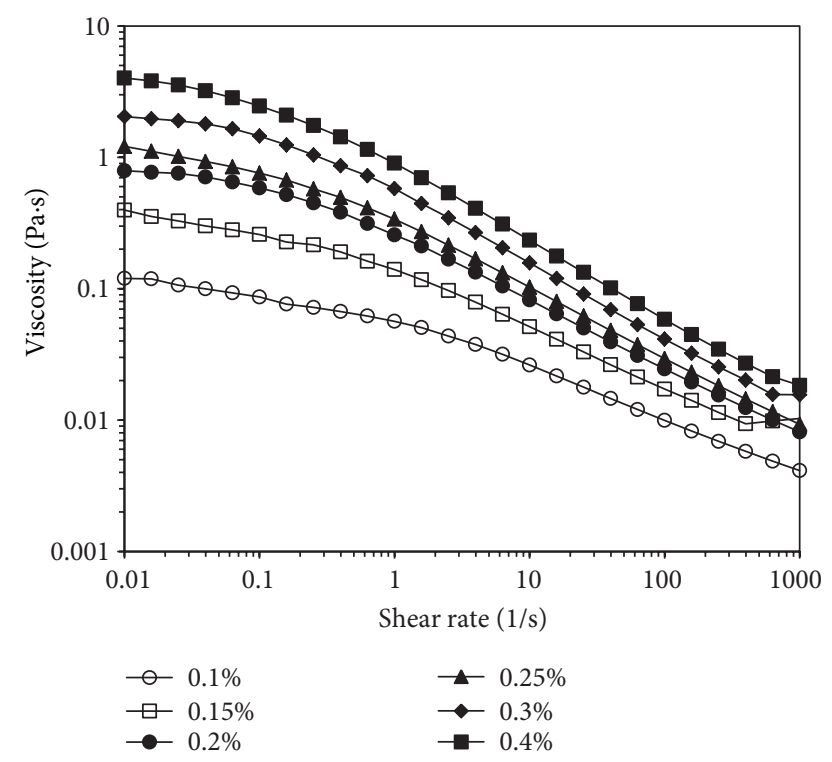

FIGURE 11: Steady state viscosity profile of SP solutions with varying concentration of copolymer at $50^{\circ} \mathrm{C}$.

Viscosity at zero shear decreases with the increase in $\mathrm{NaCl}$ concentration. Similar trend was also observed for storage modulus. Addition of salts brings counterions in the system which reduces the stretching in polymer chains by charge screening and resulting in reduction in viscosity and storage modulus. A reduction in viscosity was also observed for sodium sulphate as shown in Figure 18. With calcium chloride and magnesium chloride precipitation of SP system was observed. With sea water there was also precipitation, but dilution of sea water to $25 \%$ sea water and $75 \%$ DW gives a clear solution. This observation shows that this SP system should be limited to environment having low divalent cations. In the absence of divalent cations this SP system

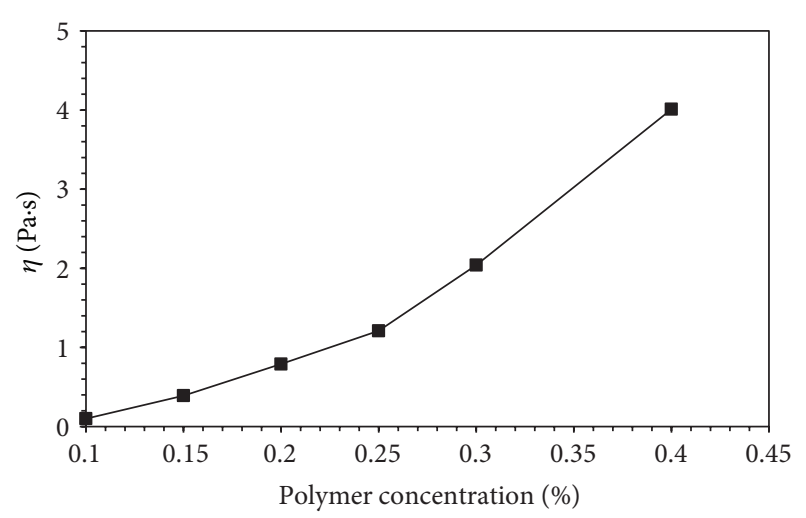

FIGURE 12: Effect of copolymer concentration on viscosity of SP solution at $50^{\circ} \mathrm{C}$ and shear rate of $0.01 \mathrm{~s}^{-1}$.

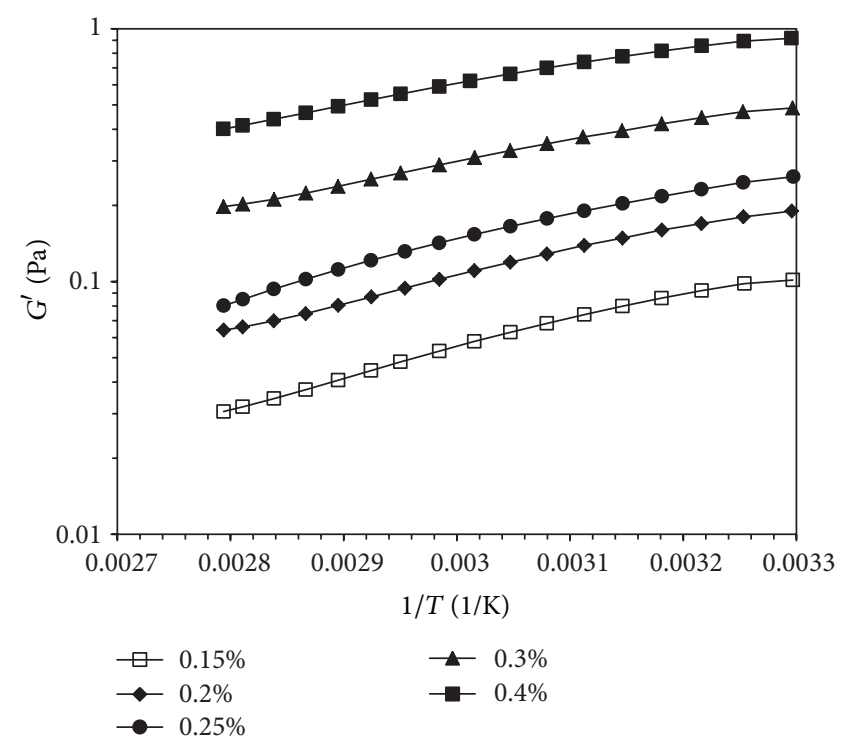

FIGURE 13: Effect of copolymer concentration on storage modulus of SP solution at different temperatures.

can be used even at high salinities. Figure 19 presents a comparison of the impact of different counterions on the steady shear viscosity of copolymer. Compared to deionized water, viscosity of polymer is lower in $0.01 \mathrm{M} \mathrm{NaCl}$ solution. But this viscosity is still higher than that of SP solution in $0.01 \mathrm{M} \mathrm{NaCl}$ having a surfactant. Both surfactant and salts are bringing counterions. System having surfactant has more counterions and introducing additional chain collapse. It is also clear from Figure 19 that decrease in viscosity is higher for polymer solution having calcium ions as compared to monovalent sodium ions. Divalency is the major cause of reduction in viscosity.

\section{Conclusions}

About $60 \%$ reduction in viscosity for HPAM was observed by increasing temperature from $50^{\circ} \mathrm{C}$ to $90^{\circ} \mathrm{C}$. However, 


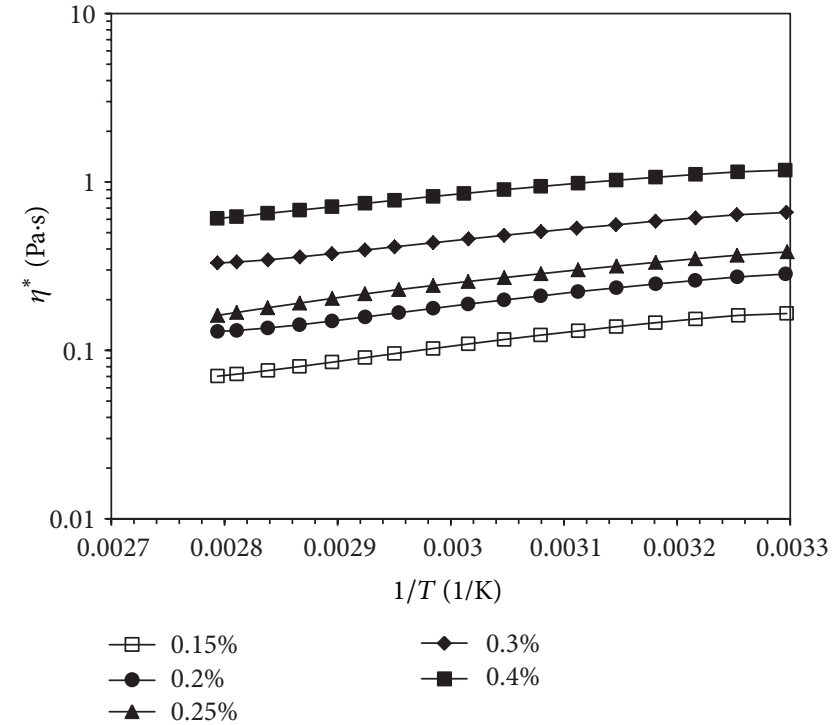

FIGURE 14: Effect of copolymer concentration on viscosity of SP solutions at different temperatures.

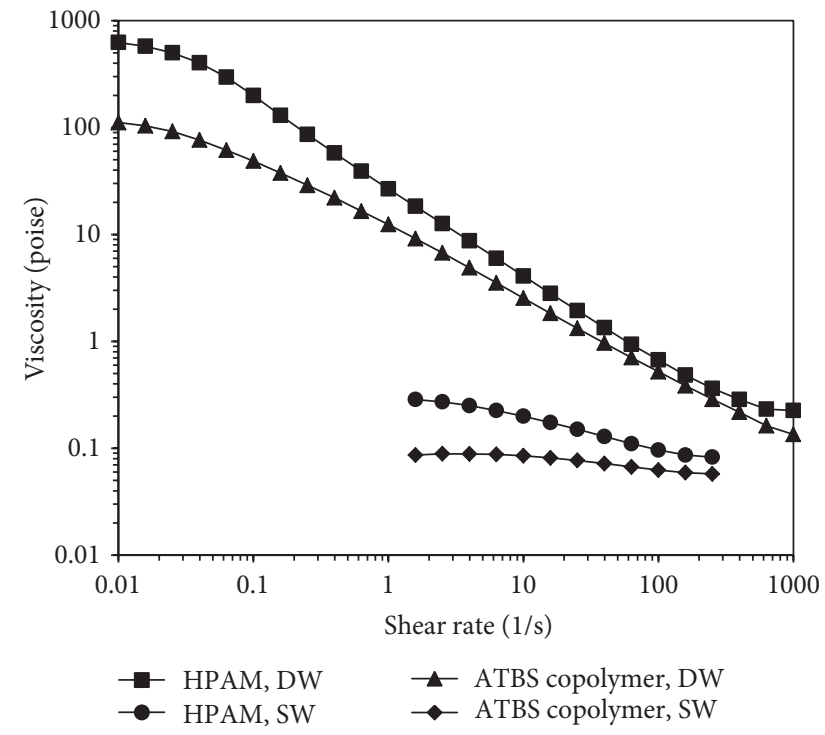

FIGURE 15: Effect of sea water on steady shear viscosity of HPAM and ATBS-AM copolymer without any surfactant at $50^{\circ} \mathrm{C}$.

decrease in viscosity for ATBS-AM copolymer was $15 \%$ for the same temperature range. It can be seen from temperature sweep experiments that at $90^{\circ} \mathrm{C}$ there was a continuous decrease of storage modulus of HPAM. Copolymer did not show significant decrease in storage modulus and viscosity within the experimental time. Copolymer of acrylamide and acrylamido tertiary butyl sulfonate (ATBS) has better performance at higher temperatures as compared to partially hydrolyzed polyacrylamide. SP system consisting of AMATBS copolymer and SDS showed better performance from rheological point of view at high temperature compared to previously reported HPAM/SDS system. Presence of anionic surfactant SDS is also a source of reduction in the viscosity

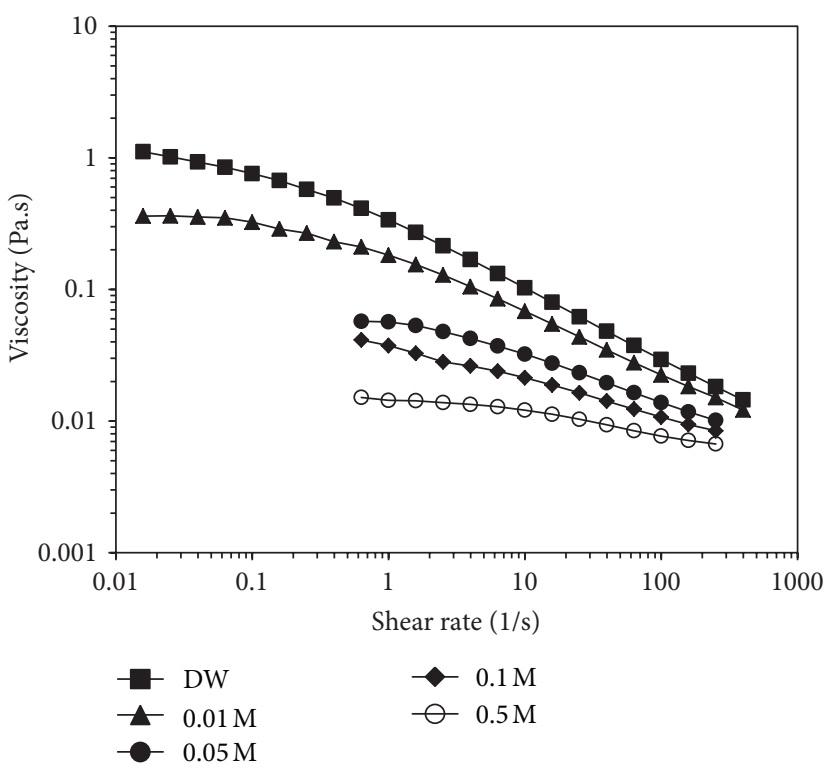

FIGURE 16: Effect of sodium chloride concentration on steady shear viscosity of copolymer at $50^{\circ} \mathrm{C}$.

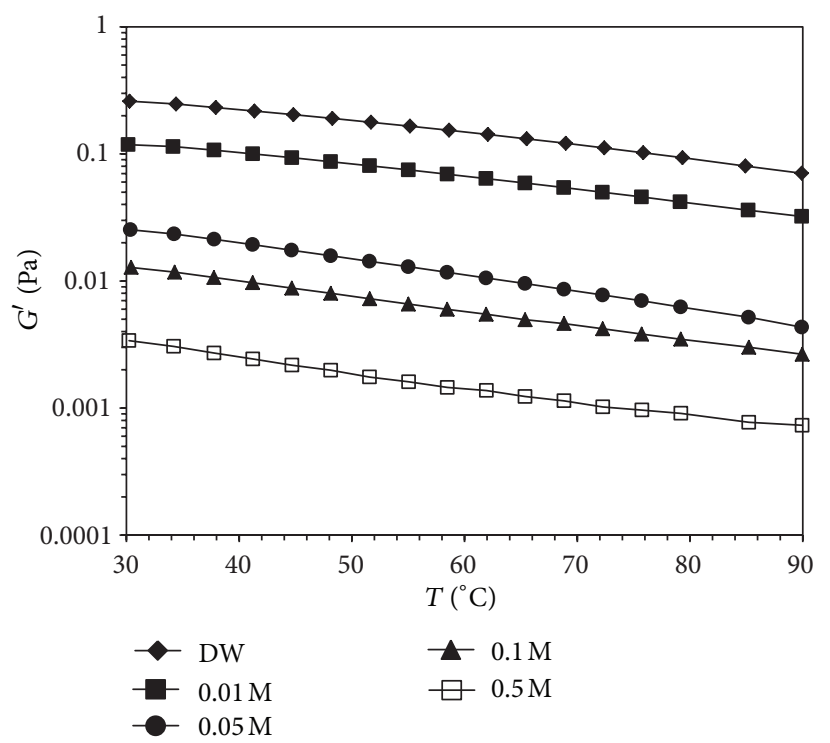

FIGURE 17: Effect of sodium chloride concentration on storage modulus of copolymer at different temperatures.

and storage modulus of polymer solution. Interfacial rheology experiments showed that this surfactant is significantly weakening the interface between SP solution and oil. Effect of each salt on the rheological properties of SP solution was investigated. There is a decrease in the viscosity in the presence of monovalent cations. In the presence of divalent cations precipitation was observed. There was precipitation with sea water. Dilution of this sea water by a ratio of $1: 3$ with DW yields a solution with no precipitation. Both polymers can be potential candidate for low temperature and low salinity reservoirs. HPAM is not suitable for high temperature 


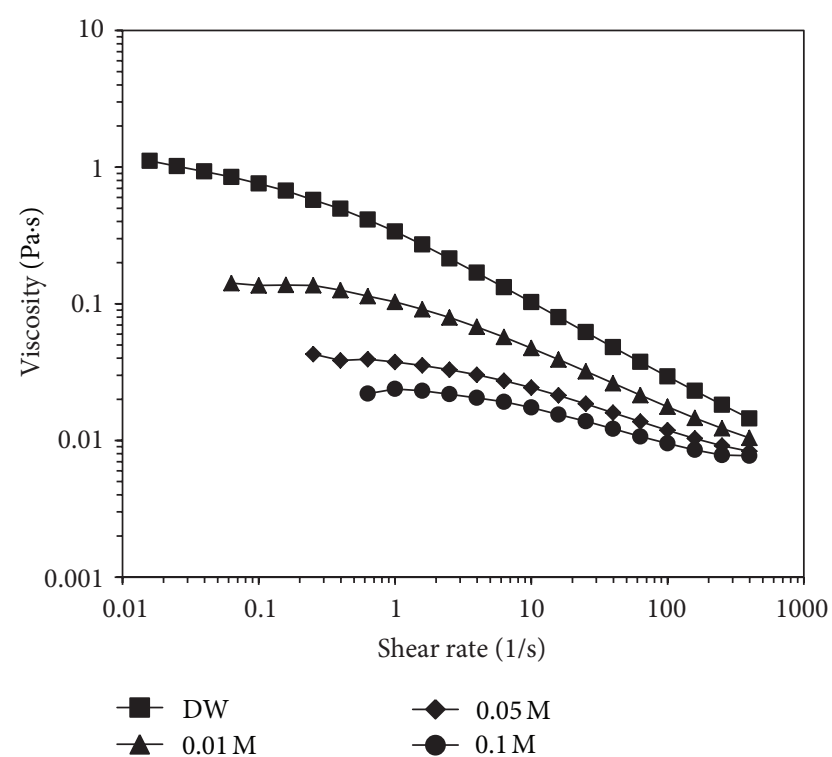

FIGURE 18: Effect of sodium sulphate concentration on steady shear viscosity of copolymer at $50^{\circ} \mathrm{C}$.

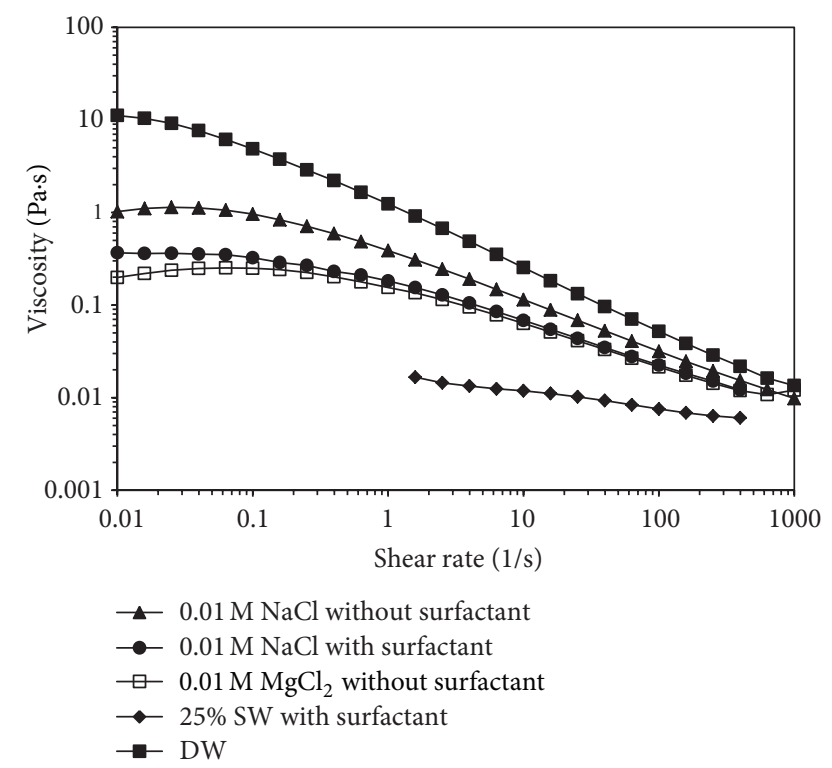

FIGURE 19: Effect of different salt on steady shear viscosity of copolymer at $50^{\circ} \mathrm{C}$.

reservoirs while ATBS based copolymer can be a potential candidate for high temperature reservoirs.

\section{Acknowledgments}

This research is supported by Saudi Aramco through Project no. CPM 2297. The authors would like to thank King Fahd University of Petroleum \& Minerals (KFUPM) for supporting this research. SNF is also acknowledged for providing polymer samples.

\section{References}

[1] D. Wang, J. Cheng, H. Xia, Q. Li, and J. Shi, "Viscous elastic fluids can mobilize oil remaining after water flood by force parallel to the oil water interface," in SPE Asia Pacific Improved Oil Recovery Conference Proceedings, Kuala Lumpur, Malaysia, 2001.

[2] T. S. Urbissinova, J. Trivedi, and E. Kuru, "Effect of elasticity during viscoelastic polymer flooding: a possible mechanism of increasing the sweep efficiency," in SPE Western Regional Meeting Proceeding, pp. 747-758, Anaheim, Calif, USA, May 2010.

[3] D. Wang, H. Xia, Z. Liu, A. Anda, and Q. Yang, "Study of the mechanism of polymer solution with visco-elastic behavior increasing microscopic oil displacement efficiency and the forming of steady "oil thread" flow channels," in SPE Asia Pacific Oil and Gas Conference and Exhibition Proceedings, Jakarta, Indonesia, April 2001.

[4] H. Xia, D. Wang, J. Wu, and F. Kong, "Elasticity of HPAM solutions increases displacement efficiency under mixed wettability conditions," in SPE Asia Pacific Oil and Gas Conference and Exhibition Proceedings, Perth, Australia, 2004.

[5] W. Wu, D. Wang, and H. Jiang, "Effect of the visco-elasticity of displacing fluids on the relationship of capillary number and displacement efficiency in weak oil-wet cores," in SPE Asia Pacific oil \& Gas Conference and Exhibition, pp. 556-560, Jakarta, Indonesia, November 2007.

[6] H. Xia, Y. Ju, F. Kong, and J. Wu, "Effect of elastic behavior of HPAM solutions on displacement efficiency under mixed wettability conditions," in Proceedings of the SPE International Petroleum Conference in Mexico, pp. 171-178, Puebla, Mexico, November 2004.

[7] Z. Zhang, J. Li, and J. Zhou, "Microscopic Roles of "Viscoelasticity" in HPMA polymer flooding for EOR," Transport in Porous Media, vol. 86, no. 1, pp. 199-214, 2011.

[8] S. K. Veerabhadrappa, T. S. Urbissinova, J. J. Trivedi, and E. Kuru, "Polymer screening criteria for EOR application-a rheological characterization approach," in Society of Petroleum Engineers Western North American Regional Meeting, pp. 386396, Anchorage, Alaska, USA, May 2011.

[9] Y. Wang, Z. Lu, Y. Han, Y. Feng, and C. Tang, "A novel thermoviscosifying water-soluble polymer for enhancing oil recovery from high-temperature and high-salinity oil reservoirs," Advanced Materials Research, vol. 306-307, pp. 654-657, 2011.

[10] X. Liu, Y. Wang, Z. Lu, Q. Chen, and Y. Feng, "Effect of inorganic salts on viscosifying behavior of a thermoassociative watersoluble terpolymer based on 2-acrylamido-methylpropane sulfonic acid," Journal of Applied Polymer Science, vol. 125, pp. 4041-4048, 2012.

[11] Q. Chen, Y. Wang, Z. Lu, and Y. Feng, "Thermoviscosifying polymer used for enhanced oil recovery: rheological behaviors and core flooding test," Polymer Bulletin, vol. 70, pp. 391-401, 2013.

[12] L. Petit, C. Karakasyan, N. Pantoustier, and D. Hourdet, "Synthesis of graft polyacrylamide with responsive self-assembling properties in aqueous media," Polymer, vol. 48, no. 24, pp. 70987112, 2007.

[13] C. Methemitis, M. Morcellet, J. Sabbadin, and J. Francois, "Interactions between partially hydrolyzed polyacrylamide and ionic surfactants," European Polymer Journal, vol. 22, no. 8, pp. 619-627, 1986. 
[14] M.-R. Caputo, J. Selb, and F. Candau, "Effect of temperature on the viscoelastic behaviour of entangled solutions of multisticker associating polyacrylamides," Polymer, vol. 45 , no. 1, pp. 231240, 2004.

[15] A. Mandal and K. Ojha, "Optimum formulation of alkalinesurfactant-polymer systems for enhanced oil recovery," in SPE Asia Pacific Oil \& Gas Conference and Exhibition, pp. 360-371, Perth, Australia, October 2008.

[16] L. Tennouga, K. Medjahed, A. Mansri, B. Bouras, and B. Grassl, "Interaction between weak neutralized polyelectrolyte complex polyacrylamide/poly(4-vinylpyridine) and sodium dodecyl sulfate in saline medium," Der Pharma Chemica, vol. 4, no. 3, pp. 1089-1092, 2012.

[17] H. T. Bu, Z. Z. Yang, and L. Huang, "Effect of thermal history on rheological properties of partially hydrolyzed polyacrylamide/anionic surfactant SDS complex systems," Chinese Chemical Letters, vol. 13, no. 5, pp. 456-459, 2002.

[18] H.-T. Bu, Z.-Z. Yang, and Y.-X. Zhang, "Experimental characterization of fluorocarbon-modified polyacrylamide/surfactant aqueous solutions," Chinese Journal of Polymer Science, vol. 21, no. 3, pp. 297-302, 2003.

[19] M. D. G. Miguel, H. D. Burrows, S. J. Formosinho, and B. Lindman, "Fluorescence studies of polymer-surfactant association," Journal of Molecular Structure, vol. 563-564, pp. 89-98, 2001.

[20] L. Tofani, A. Feis, R. E. Snoke, D. Berti, P. Baglioni, and G. Smulevich, "Spectroscopic and interfacial properties of myoglobin/surfactant complexes," Biophysical Journal, vol. 87, no. 2, pp. 1186-1195, 2004.

[21] J. Mata, J. Patel, N. Jain, G. Ghosh, and P. Bahadur, "Interaction of cationic surfactants with carboxymethylcellulose in aqueous media," Journal of Colloid and Interface Science, vol. 297, no. 2 , pp. 797-804, 2006.

[22] K. Y. Mya, A. M. Jamieson, and A. Sirivat, "Interactions between the nonionic surfactant and polyacrylamide studied by light scattering and viscometry," Polymer, vol. 40 , no. 21 , pp. 57415749, 1999.

[23] R. López-Esparza, M.-A. Guedeau-Boudeville, Y. Gambin, C. Rodríguez-Beas, A. Maldonado, and W. Urbach, "Interaction between poly(ethylene glycol) and two surfactants investigated by diffusion coefficient measurements," Journal of Colloid and Interface Science, vol. 300, no. 1, pp. 105-110, 2006.

[24] M. Hai and B. Han, "Study of interaction between sodium dodecyl sulfate and polyacrylamide by rheological and conductivity measurements," Journal of Chemical and Engineering Data, vol. 51, no. 5, pp. 1498-1501, 2006.

[25] S.-C. Wang, T.-C. Wei, W.-B. Chen, and H.-K. Tsao, "Effects of surfactant micelles on viscosity and conductivity of poly(ethylene glycol) solutions," Journal of Chemical Physics, vol. 120, no. 10, pp. 4980-4988, 2004.

[26] A. Capalbi and C. La Mesa, "Polymer-surfactant interactions," Journal of Thermal Analysis and Calorimetry, vol. 66, no. 1, pp. 233-241, 2001.

[27] M. Y. Khan, A. Samanta, K. Ojha, and A. Mandal, "Interaction between aqueous solutions of polymer and surfactant and its effect on physicochemical properties," Asia-Pacific Journal of Chemical Engineering, vol. 3, no. 5, pp. 579-585, 2008.

[28] A. A. Mohsenipour, R. Pal, and K. Prajapati, "Effect of cationic surfactant addition on the drag reduction behaviour of anionic polymer solutions," The Canadian Journal of Chemical Engineering, vol. 91, pp. 181-189, 2013.

[29] H. M. Kopperud, F. K. Hansen, and B. Nyström, "Effect of surfactant and temperature on the rheological properties of aqueous solutions of unmodified and hydrophobically modified polyacrylamide," Macromolecular Chemistry and Physics, vol. 199, no. 11, pp. 2385-2394, 1998. 

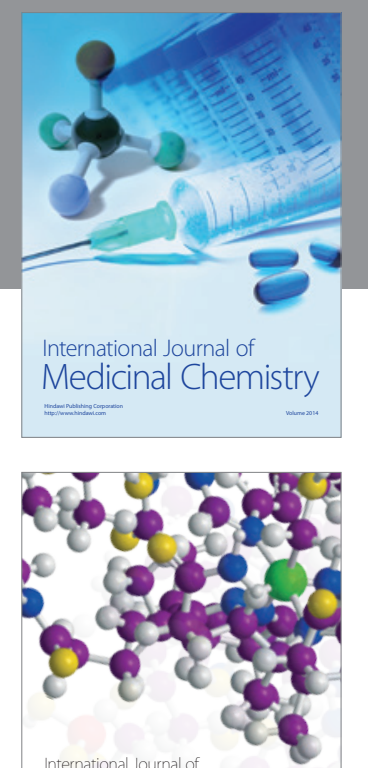

\section{Carbohydrate} Chemistry

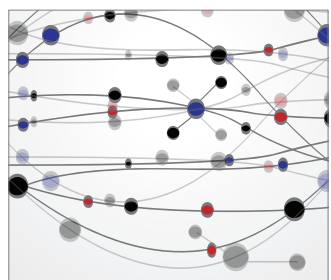

The Scientific World Journal
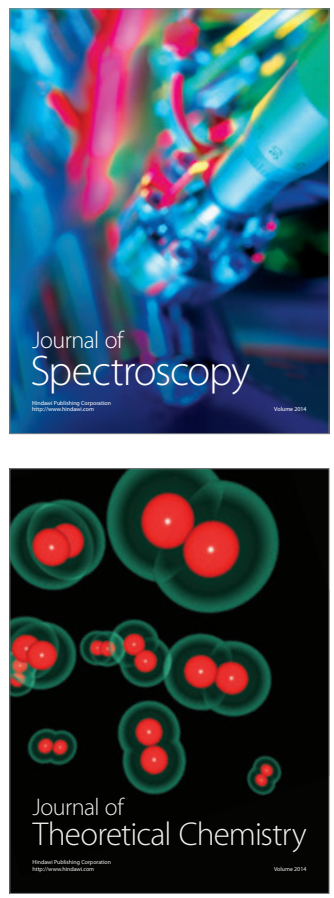
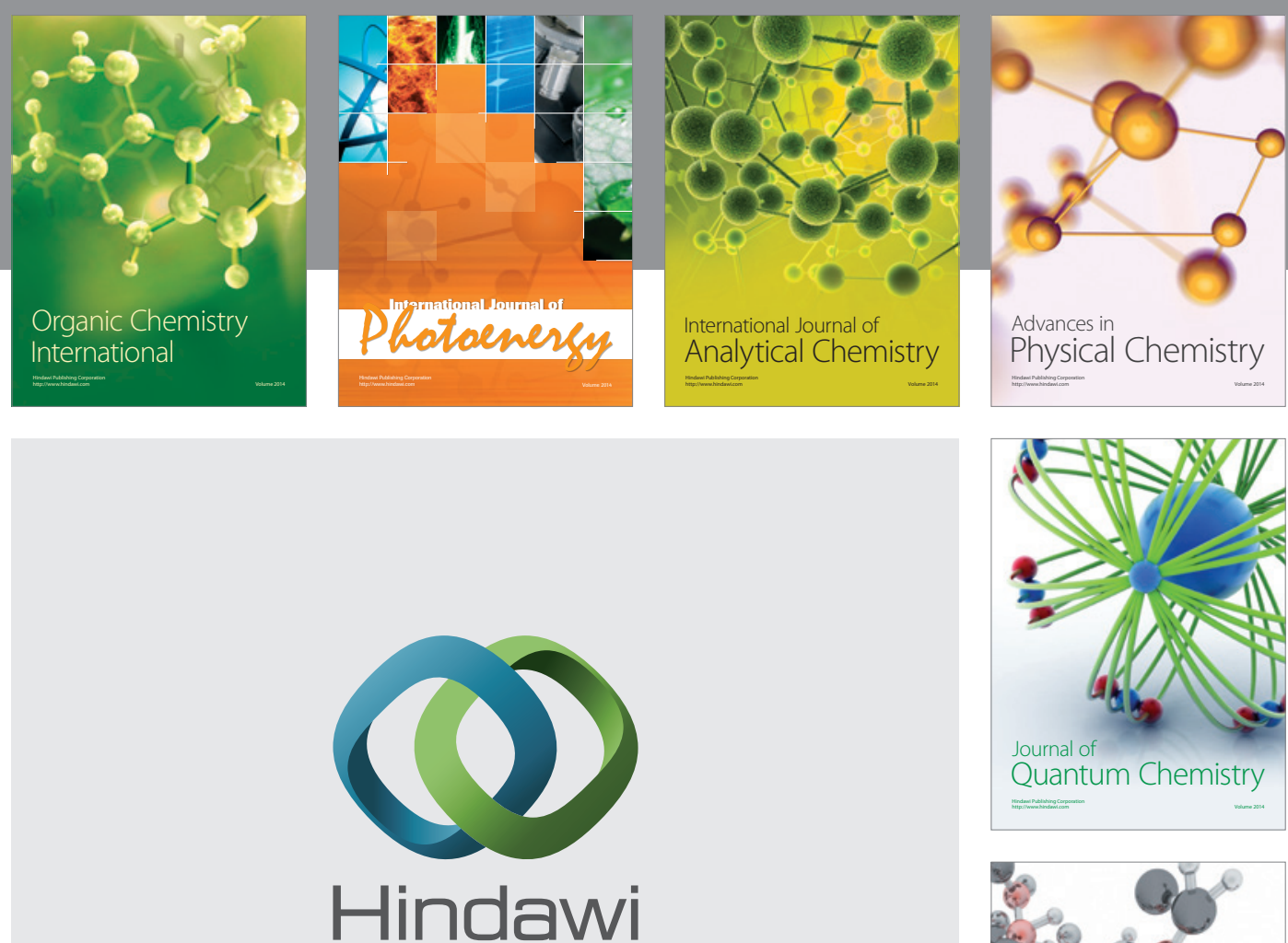

Submit your manuscripts at

http://www.hindawi.com

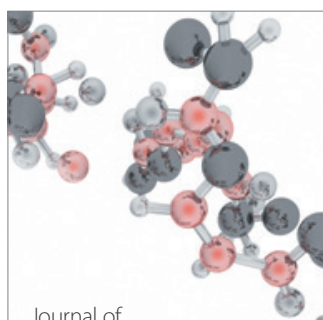

Analytical Methods

in Chemistry

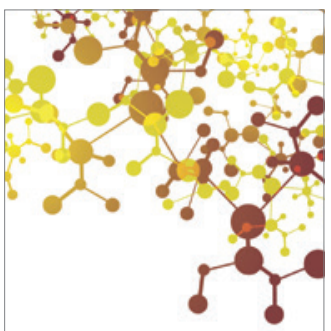

Journal of

Applied Chemistry

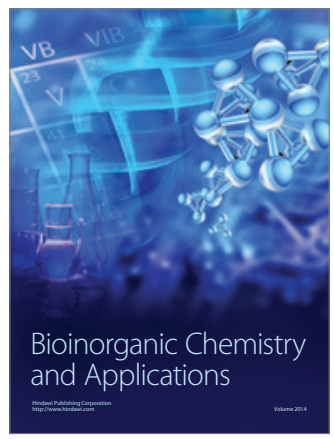

Inorganic Chemistry
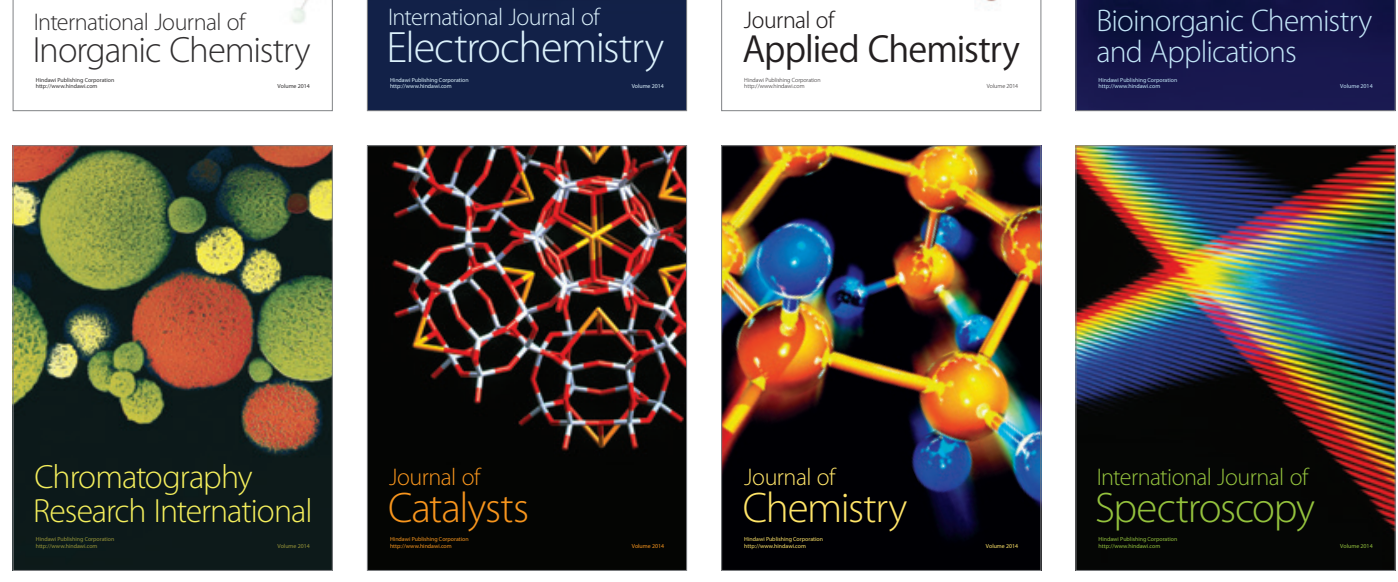